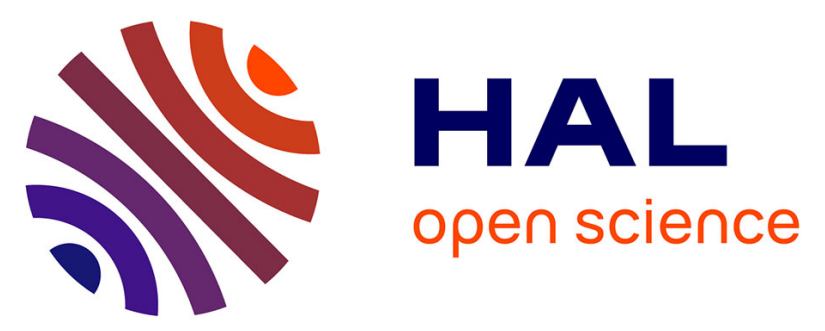

\title{
Relations Between Landsat Spectral Reflectances and Land Surface Emissivity Over Bare Soils
}

Albert Olioso, Xavier Briottet, Sophie Fabre, Frédéric Jacob, Aurelie Michel, Simon Nativel, Vincent Rivalland, Jean-Louis Roujean

\section{To cite this version:}

Albert Olioso, Xavier Briottet, Sophie Fabre, Frédéric Jacob, Aurelie Michel, et al.. Relations Between Landsat Spectral Reflectances and Land Surface Emissivity Over Bare Soils. IGARSS 2019, Jul 2019, Yokohama, Japan. IEEE, IGARSS 2019 - 2019 IEEE International Geoscience and Remote Sensing Symposium, pp.6937-6940, 10.1109/IGARSS.2019.8899275 . hal-02443589

\section{HAL Id: hal-02443589 \\ https://hal.science/hal-02443589}

Submitted on 31 May 2021

HAL is a multi-disciplinary open access archive for the deposit and dissemination of scientific research documents, whether they are published or not. The documents may come from teaching and research institutions in France or abroad, or from public or private research centers.
L'archive ouverte pluridisciplinaire HAL, est destinée au dépôt et à la diffusion de documents scientifiques de niveau recherche, publiés ou non, émanant des établissements d'enseignement et de recherche français ou étrangers, des laboratoires publics ou privés. 


\title{
RELATIONS BETWEEN LANDSAT SPECTRAL REFLECTANCES AND LAND SURFACE EMISSIVITY OVER BARE SOILS
}

\author{
Albert Olioso $^{(1)}$, Xavier Briottet ${ }^{(2)}$, Sophie Fabre ${ }^{(2)}$, Frédéric Jacob ${ }^{(3)}$, Aurélie Michel ${ }^{(2)}$, Simon \\ Nativel $^{(2,4)}$, Vincent Rivalland ${ }^{(4)}$ and Jean-Louis Roujean ${ }^{(4)}$ \\ ${ }^{(1)}$ UMR EMMAH, INRA-Université d'Avignon et des Pays de Vaucluse, Avignon, France; \\ ${ }^{(2)}$ ONERA DOTA, Toulouse, France; ${ }^{(3)}$ UMR LISAH, IRD-INRA-SUPAGRO, Montpellier, France; \\ ${ }^{(4)}$ UMR CESBIO, UPS-CNRS-CNES-IRD, Toulouse, France \\ (correspondance to albert.olioso@inra.fr)
}

\begin{abstract}
Land surface emissivity is required for deriving surface temperature from thermal infrared radiances. When using single-channel or two-channel thermal infrared sensors, information on emissivity may be derived from spectral reflectance measurements through regression models. In this study, we present relationships derived over bare soils for Landsat 7 - ETM+ sensor. Reflectances in ETM+ channels were obtained from soil spectra (between 0.4 and $13 \mu \mathrm{m}$ ) extracted from the ASTER spectral library and the dataset acquired by Lesaignoux et al. (2013). The best relations were obtained between reflectances in the mid-infrared channels (ETM5 and ETM7) and the thermal infrared channel (ETM6) with correlation coefficients of 0.63 and 0.72 respectively. The relations were mostly generated by the variations of soil reflectances due to changes in soil moisture. Correlations were lower when considering the variations due to soil type.
\end{abstract}

Index Terms-Emissivity, Thermal Infrared, Landsat, Soil

\section{INTRODUCTION}

Land Surface Emissivity (LSE) is required for deriving surface temperature from thermal infrared (TIR) radiances [1][2]. Surface temperature is a very important land surface variable for monitoring energy and water exchanges over land surfaces [3][4][5]. Thermal sensors with at least 3 thermal channels (MODIS, VIIRS, ASTER...) can provide spectral emissivity and surface temperature thanks to methods such as the TES algorithm (Temperature Emissivity Separation [6][7]). When considering sensors with one or two spectral bands, emissivity has to be set from independent information. This is the case for sensors on board of LANDSAT platforms. [8] and [9] showed that LSE was usually increasing with vegetation amount and that a vegetation indices such as the Normalized Difference Vegetation Index $(N D V I)$ can be used to estimate emissivity. This was confirmed later by [10][11] for example. In some situations, when soil has a very high emissivity or when plants are dry, emissivity can be decreasing while NDVI increases [12]. Mira et al. [11] used a simple exponential model to relate emissivity $\varepsilon$ to NDVI:

$$
\varepsilon=\varepsilon_{\infty}-\left(\varepsilon_{\infty}-\varepsilon_{S}\right)\left(\frac{N D V I-N D V I_{\infty}}{N D V I_{S} N D V I_{\infty}}\right)^{k}
$$

where subscript $s$ stands for bare soil conditions and subscript $\infty$ for full vegetation canopy cover. $k$ is a parameter mainly related to canopy architecture and geometry of remote sensing data acquisition. This model was built using the same method as models relating the fraction of absorbed photosynthetically active radiation (fAPAR) to vegetation indices [13]. Other model forms were proposed by [8] [10][14][15].

One of the main issues related to the potential use of such model is related to the soil value, represented by parameter $\varepsilon_{s}$, which may be the main factor of variation of emissivity over land surface. Bare soil emissivity varies as a function of many factors including soil types, mineral composition, surface soil moisture and roughness ([16][17] [18]). Sobrino et al. [14] related soil surface emissivity to reflectances in the solar domain and in particular to reflectances in red bands that are available for most of the Earth observation sensors. For TM they proposed the following expression:

$$
\varepsilon_{\text {TME }}=0.979-0.035 \rho_{\text {TM8 }}
$$

where $\varepsilon_{T M 6}$ was the emissivity in band 6 and $\rho_{T M 3}$ the reflectance in channel 3 . This equation was trained over 49 soil spectra acquired in laboratory conditions.

Relating emissivity to red reflectance was first proposed by [15] for estimating soil emissivity from AVHRR sensors that included only two bands in the reflective domain. Other sensors, such as MODIS or TM, ETM+ and OLI on board of the successive Landsat 5, 7 and 8 platforms have more 
bands in this spectral domain. A new analysis is required for evaluating if the red band is the most suitable band for estimating soil emissivity or if other bands should be used instead.

New soil data, combining VISIR and TIR spectra were acquired by Lesaignoux et al. [18] including 32 types of soil with around 6 levels of moisture content. The analysis of this dataset provides new opportunities for investigating the relationship between spectral reflectances in the solar domain and thermal emissivities. In this paper, we present a preliminary analysis of these data in combination to the ASTER spectral library with the objective to establish new relationships that can be used to estimate bare soil emissivity from Landsat reflective bands.

\section{MATERIAL AND METHODS}

Soil reflectance spectra between 0.4 and $13 \mu \mathrm{m}$ were obtained from the ASTER spectral library V2 [19] and the Lesaignoux spectral library (noted LSL here) [18]. The ASTER spectral library included 41 reflectance spectra, all of them acquired in dry conditions, covering the whole spectral range required in this study (Figure 1). Nowadays, the ASTER library is not anymore available. It has been replaced by the ECOSTRESS spectral library which contains the same soil spectra. The LSL database included 190 reflectance spectra measured over 32 soil samples with five to seven soil moisture levels (Figure 1). Samples were obtained from various agricultural soils in South of France.

Soil reflectance values in the channels of the Landsat 7ETM+ sensor (Table 1) were computed by convoluting soil spectra with channels spectral response. Correlation coefficients were calculated between the reflective bands and the thermal band for each database and for the whole set of data. As the ASTER library contained only spectra for dry soils, we also considered merging the ASTER library with the data acquired over dry soils in LSL. Eventually, linear regressions were computed for the spectral bands with the best correlation coefficients. The analysis was performed over spectral reflectance spectra $(\rho)$ in the whole domain. Emissivity $(\varepsilon)$ in the thermal domain would be retrieved as:

$$
\varepsilon=1-\rho
$$

Table 1: ETM+ spectral ranges

\begin{tabular}{|c|c|c|}
\hline Band number & Spectral range $(\mu \mathrm{m})$ & \multirow{2}{*}{ Spectral domain } \\
\hline 1 & $0.441-0.514$ & \multirow{2}{*}{ Visible } \\
\hline 2 & $0.519-0.601$ & \\
\hline 3 & $0.631-0.692$ & near-infrared \\
\hline 4 & $0.772-0.898$ & mid-infrared \\
\hline 5 & $1.547-1.749$ & thermal-infrared \\
\hline 6 & $10.31-12.36$ & mid-infrared \\
\hline 7 & $2.064-2.345$ & panchromatic \\
\hline 8 & $0.515-0.896$ & \\
\hline
\end{tabular}
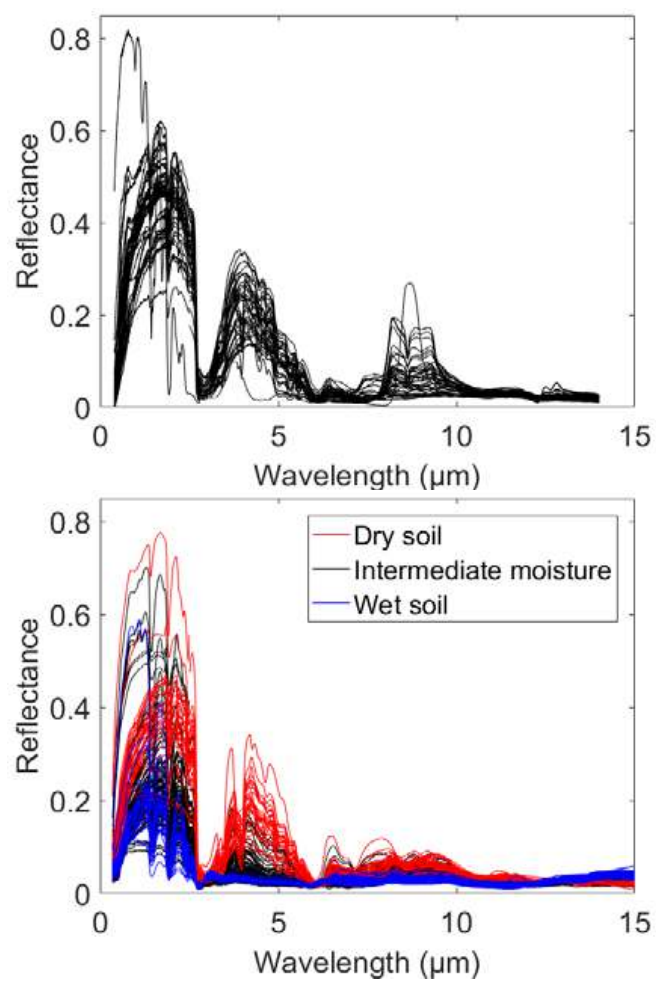

Figure 1: soil spectra in the ASTER database (top) and the LSL library (bottom)

\section{RESULTS}

Table 2 presents the correlation coefficients that were obtained over the two databases and the merged database between the thermal band (ETM6) and the reflective bands. Correlation coefficients were higher than 0.5 for almost all bands in LSL, while no correlation were obtained for most of the bands in the ASTER database. For both databases, the best correlations where obtained for the bands in the mid infrared and in particular for ETM7. When combining the two databases, the correlation coefficient was 0.72 for ETM7 and 0.63 for ETM5. Correlation coefficients obtained over dry spectra were very low. Figure 2 presents the relations between ETM6 and the 2 most correlated bands (ETM5 and ETM7) as well as with the red band (ETM3) that was previously used by [14][15] (in red ASTER database, in blue LSL database). Linear regressions between ETM6 and ETM3, ETM5 and ETM7 are also shown for the various datasets (global, LSL, dry soil). Linear regressions coefficients and evaluations are given in Table 3 according to the following notation (i being 3, 5 or 7):

$$
\rho_{\text {FTMG }}=a+b \rho_{F T M t}
$$



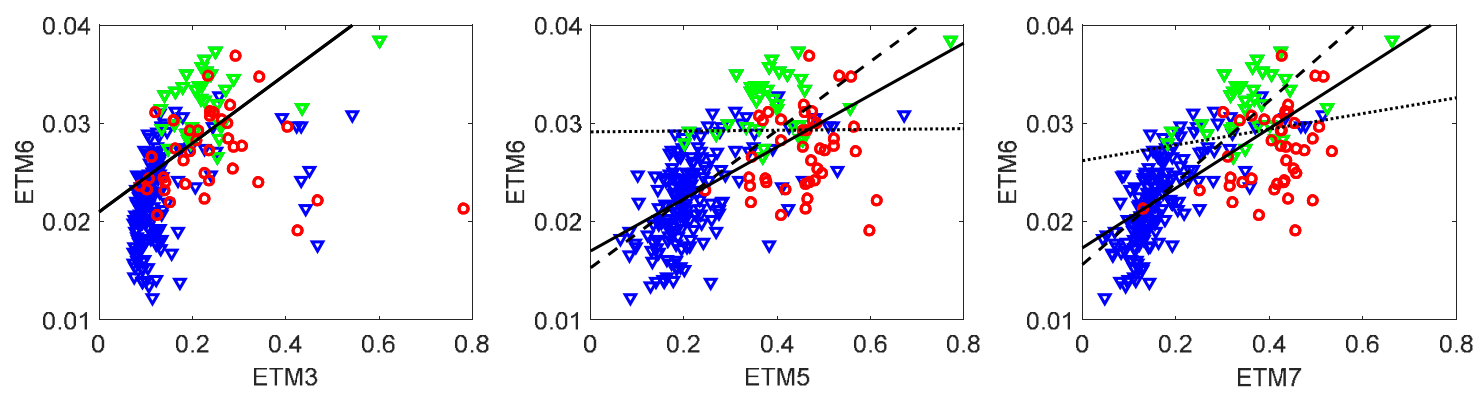

Figure 2: relations between reflectances in ETM6 and ETM3 (left), ETM5 (centre) and ETM7 (right). $\nabla:$ LSL data, $\nabla$ : LSL dry data, o: ASTER data; Black line; regression over the whole dataset; dashed line: regression over LSL; dotted line: regression over the dry soils data.

The Root Mean Square Errors when fitting the linear regressions ranged between 0.003 and 0.005 . They were larger $(0.005$ to 0.007$)$ when the linear equations were applied to the remaining part of the dataset (regressions trained over LSL and evaluated on ASTER dataset and regression trained over dry soils data and evaluated on wet soils). The RMSE obtained when applying Eq. 2 from [14] was 0.007 .

Table 2: correlation coefficients of reflective bands with the thermal band

\begin{tabular}{|c|c|c|c|c|}
\hline Band & ASTER library & LSL library & Global & Dry \\
\hline 1 & -0.13 & 0.48 & 0.37 & 0.15 \\
\hline 2 & -0.10 & 0.51 & 0.42 & 0.08 \\
\hline 3 & -0.06 & 0.52 & 0.44 & 0.03 \\
\hline 4 & -0.02 & 0.52 & 0.47 & 0.03 \\
\hline 5 & 0.15 & 0.70 & 0.63 & 0.01 \\
\hline 7 & $\mathbf{0 . 3 4}$ & $\mathbf{0 . 8 1}$ & $\mathbf{0 . 7 2}$ & $\mathbf{0 . 1 5}$ \\
\hline 8 & -0.05 & 0.52 & 0.45 & 0.07 \\
\hline
\end{tabular}

Table 3: coefficients and evaluations of linear regressions between mid-infrared and thermal bands

\begin{tabular}{|l|c|c|c|c|}
\hline & $\mathrm{a}$ & $\mathrm{b}$ & RMSE & $\begin{array}{c}\text { RMSE on } \\
\text { remaining } \\
\text { data }\end{array}$ \\
\hline$\rho_{\text {ETM5 }}$, global & 0.026 & 0.017 & 0.0043 & - \\
\hline$\rho_{\text {ETM5 }}$, LSL & 0.035 & 0.015 & 0.0040 & 0.0061 \\
\hline$\rho_{E T M 5}$, dry & 0.000 & 0.029 & 0.0045 & 0.0082 \\
\hline$\rho_{E T M 7}$, global & 0.030 & 0.017 & 0.0038 & - \\
\hline$\rho_{E T M 7}$, LSL & 0.042 & 0.016 & 0.0033 & 0.0070 \\
\hline$\rho_{E T M 7}$, dry & 0.008 & 0.026 & 0.0044 & 0.0066 \\
\hline
\end{tabular}

The relation between ETM7 and ETM6 over the LSL database presented a possible non-linear behavior that was represented by the following hand-fitted equation (Figure $3)$ :

$$
\rho_{\text {ETMG }}=0.035\left(1-e^{-\frac{\rho_{\text {ETMET }}}{0.15}}\right)
$$

with fitting performances similar to the best linear fit $(\mathrm{RMSE}=0.0033)$. Application to ASTER data gave slightly better performances (RMSE $=0.0065$ vs. 0.0070$)$.

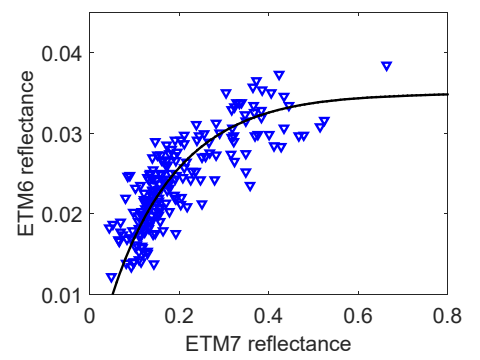

Figure 3: non-linear fit for ETM6 vs. ETM7 on LSL data.

\section{DISCUSSION AND CONCLUSION}

The results obtained on our dataset (LSL + ASTER) showed that the variability of the relation between the reflective domain and the thermal domain (in ETM+ bands) was lower in the mid-infrared domain. In the visible and the nearinfrared, variations in reflectances between the different soils were large while reflectances in ETM6 were in a very limited range whatever the soil type. For example, one soil in LSL is very bright even in wet situations.

The ASTER library contains a large variability of soil types, all of them in dry conditions. One of the soils, corresponding to almost pure gypsum sand, has a very peculiar spectrum. The LSL library has a more limited range of soil types (for example it does not include sandy soils), but each soil sample was measured at several levels of soil moisture which generated variations in soil brightness both in the reflective and the thermal domains. These variations were well correlated and a possible non-linear relation was identified between ETM6 and ETM7 providing slightly better results than a linear relation over the LSL.

When only considering dry soils (ASTER or ASTER+LSL), correlations between reflective bands and the thermal band reflectance were close to zero, showing that the variability in soil types is not reflected in relations between bands. In that case, the best estimator of soil emissivity $\varepsilon_{s}$ was the average value $0.971(=1-0.029)$. This generated an error larger than 0.004 . 
When considering all type of soils together, significative correlation between the thermal band and the bands in the mid-infrared domain existed. A linear relation between ETM7 and ETM6 was found that can be used for estimating soil surface emissivity with a fitting RMSE also around 0.004 . At the moment, this relation has not been evaluated over independent dataset.

The dataset used in this study was obtained by combining two sources of data which were acquired with different sampling protocols and measurement devices. The representativeness of the global dataset is not established, as it is shown when comparing the composition of the ASTER library (large diversity of soil, but all in dry conditions) and the LSL library (lower diversity of soil, but with changing moisture). The acquisition of new spectra spanning from visible to thermal infrared at different soil moisture level would be very valuable, both for increasing the database representativeness and to provide data for better evaluating the quality of soil emissivity estimation.

\section{ACKNOWLEDGEMENT}

This work was made possible thanks to the financial support of CNES (Centre National d'Etudes Spatiales) through the evaluation of TOSCA committee (E2IRT project). LSL data were acquired at ONERA in the frame of projects funded by the PRF ENVIRO program (internal federative project lead at ONERA) and the PNTS (French National Program for Remote Sensing from Space).

\section{REFERENCES}

[1] T.N. Carlson, O. Taconet, A. Vidal, R.R. Gillies, A. Olioso, and K. Humes, "An overview of the workshop on thermal remote sensing held at La Londe les Maures, France, September 20-24," Agric. For. Meteor., 77, pp. 141-151, 1993.

[2] B. Tardy, V. Rivalland, M. Huc, O. Hagolle, S. Marcq, and G. Boulet, "A Software Tool for Atmospheric Correction and Surface Temperature Estimation of Landsat Infrared Thermal Data," Remote Sensing, 8, p. 696, 2016.

[3] A. Olioso, H. Chauki, D. Courault, and J.-P. Wigneron, "Estimation of evapotranspiration and photosynthesis by assimilation of remote sensing data into SVAT models", Remote Sens. Environ., 68, pp. 341-356, 1999.

[4] M.C. Anderson, R.G. Allen, A. Morse, and W.P. Kustas, "Use of Landsat thermal imagery in monitoring evapotranspiration and managing water resources", Remote Sens. Environ., 122, pp. 5065,2012 .

[5] B. Gallego-Elvira, A. Olioso, M. Mira, S. Reyes-Castillo, G. Boulet, O. Marloie, S. Garrigues, D. Courault, M. Weiss, P. Chauvelon, and O. Boutron, "EVASPA (EVapotranspiration Assessment from SPAce) tool: An overview", Proc. Environ. Sci., 19, pp. 303-310, 2013.
[6] T. J. Schmugge, S. J. Hook, and C. Coll, "Recovering surface temperature and emissivity from thermal infrared multispectral data," Remote Sens. Environ., 65, pp. 121-131, 1998.

[7] F. Jacob, A. Lesaignoux, A. Olioso, M. Weiss, K. Caillault, S. Jacquemoud, F. Nerry, A. French, T. Schmugge, X. Briottet, and J.-P. Lagouarde, "Reassessment of the temperature - emissivity separation from multispectral thermal infrared data: Introducing the impact of vegetation canopy by simulating the cavity effect with the SAIL-Thermique model," Remote Sens. Environ., 198, pp. 160-172, 2017.

[8] A.A. van de Griend, and M. Owe, "On the relationship between thermal emissivity and the normalized difference vegetation index for natural surfaces," Int. J. Remote Sens., 14, pp. 1119-1131, 1993.

[9] A. Olioso, "Simulating the relationship between thermal emissivity and the normalized difference vegetation index," Int. J. Remote Sens., 16, pp. 3211-3216, 1995.

[10] E. Valor, and V. Caselles, "Mapping land surface emissivity from NDVI: Application to European, African, and South American areas," Remote Sens. Environ., 57, pp. 167-184, 1996.

[11] M. Mira, A. Olioso, B. Gallego-Elvira, D. Courault, S. Garrigues, O. Marloie, O. Hagolle, P. Guillevic, G. Boulet, "Uncertainty assessment of surface net radiation derived from Landsat images," Remote Sens. Environ., 175, pp. 251-270, 2016.

[12] A. Olioso, G. Soria, J.A. Sobrino, and B. Duchemin, "Evidence of low land surface thermal infrared emissivity in the presence of dry vegetation," IEEE Geosc. Rem. Sens. Let., 4, pp. 112-116, 2007.

[13] F. Baret, and A. Olioso, "Estimation à partir de mesures de réflectance spectrale du rayonnement photosynthétiquement actif absorbé par une culture de blé," Agronomie, 9, pp. 885-895, 1989.

[14] J.A. Sobrino, J.C. Jiménez-Muñoz, G. Sòria, M. Romaguera, L. Guanter, J. Moreno, A. Plaza, and P. Martínez, "Land Surface Emissivity Retrieval From Different VNIR and TIR Sensors," IEEE Trans. Geosc. Rem. Sens., 46, pp. 316-327, 2008.

[15] J.A. Sobrino, and N. Raissouni, "Toward remote sensing methods for land cover dynamic monitoring: Application to Morocco.” Int. J. Remote Sens., 21, pp. 353-366, 2000.

[16] J. W. Salisbury, and D. M. D'Aria, " Emissivity of Terrestial Materials in the 8-14um Atmospheric Window," Remote Sens. Environ. 42, pp. 83-106, 1992.

[17] M. Mira, E. Valor, V. Caselles, E. Rubio, C. Coll, J.M. Galve, R. Niclos, J.M. Sanchez, R. Boluda, "Soil Moisture Effect on Thermal Infrared $(8-13-\mu \mathrm{m})$ Emissivity," IEEE Trans. Geosc. Rem. Sens., 48, pp. 2251-2260, 2010.

[18] A. Lesaignoux, S. Fabre, and X. Briottet, "Influence of soil moisture content on spectral reflectance of bare soils in the 0.4-14 $\mu \mathrm{m}$ domain," Int. J. Remote Sens., 34, pp. 2268-2285, 2013.

[19] A. M. Baldridge, S. Hook, C.I. Grove, and G. Rivera, "The ASTER spectral library version 2.0," Remote Sens. Environ., 113, pp. 711-715, 2009. 